\title{
OPERATOR FUNCTION ASSOCIATED WITH AN ORDER PRESERVING OPERATOR INEQUALITY
}

\section{TAKAYUKI FURUTA}

Abstract. A capital letter means a bounded linear operator on a Hilbert space $H$. The celebrated Löwner-Heinz inequality asserts that $A \geqslant B \geqslant 0$ ensures $A^{\alpha} \geqslant B^{\alpha}$ for any $\alpha \in[0,1]$, but $A^{p} \geqslant$ $B^{p}$ does not always hold for $p>1$. From this point of view, we obtained: If $A \geqslant B \geqslant 0$ with $A>0$, then for $t \in[0,1]$ and $p \geqslant 1$,

$$
F_{A, B}(r, s)=A^{\frac{-r}{2}}\left\{A^{\frac{r}{2}}\left(A^{\frac{-t}{2}} B^{p} A^{\frac{-t}{2}}\right)^{s} A^{\frac{r}{2}}\right\}^{\frac{1-t+r}{(p-t) s+r}} A^{\frac{-r}{2}}
$$

is a decreasing function for $r \geqslant t$ and $s \geqslant 1$, and $F_{A, A}(r, s) \geqslant F_{A, B}(r, s)$ holds, that is,

$$
A^{1-t+r} \geqslant\left\{A^{\frac{r}{2}}\left(A^{\frac{-t}{2}} B^{p} A^{\frac{-t}{2}}\right)^{s} A^{\frac{r}{2}}\right\}^{\frac{1-t+r}{(p-t) s+r}}
$$

holds for $t \in[0,1], p \geqslant 1, r \geqslant t$ and $s \geqslant 1$.

We shall prove the following further extension. Let $A \geqslant B \geqslant 0$ with $A>0, t \in[0,1]$ and $p_{1}, p_{2}, \ldots, p_{2 n} \geqslant 1$ for natural number $n$. Then

$$
\begin{aligned}
& G_{A, B}\left[r, p_{2 n}\right] \\
& =A^{\frac{-r}{2}}\left\{A^{\frac{r}{2}}[\underbrace{A^{\frac{-t}{2}}\left\{A ^ { \frac { t } { 2 } } \ldots \left[A ^ { \frac { - t } { 2 } } \left\{A ^ { \frac { t } { 2 } } \left(A^{\frac{-t}{2}}\right.\right.\right.\right.}_{A^{\frac{t}{2}} n A^{\frac{-t}{2}} n \text { times and }} B^{p_{1}} \underbrace{\left.\left.\left.\left.A^{\frac{-t}{2}}\right)^{p_{2}} A^{\frac{t}{2}}\right\}^{p_{3}} A^{\frac{-t}{2}}\right]^{p_{4}} A^{\frac{t}{2}} \ldots\right\} A^{\frac{-t}{2}}}_{A^{\frac{t}{2}} A^{\frac{-t}{2}} n \text { t turns }}]^{p_{2 n} A^{\frac{r}{2}}}\right\}^{\frac{1+r-t}{q(2 n]+r-t}} A^{\frac{-r}{2}}
\end{aligned}
$$

is a decreasing function of $p_{2 n} \geqslant 1$ and $r \geqslant t$, and the following inequality holds: $G_{A, A}\left[r, p_{2 n}\right] \geqslant$ $G_{A, B}\left[r, p_{2 n}\right]$, that is,

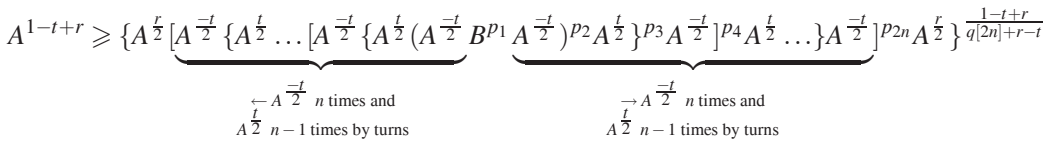

where $q[2 n]=q\left[2 n ; p_{1}, p_{2}, \ldots, p_{2 n}\right]=\underbrace{\left\{\ldots\left[\left\{\left[\left(p_{1}-t\right) p_{2}+t\right] p_{3}-t\right\} p_{4}+t\right] p_{5}-\ldots-t\right\} p_{2 n}+t}_{-t \text { and } t \text { alternately } n \text { times appear }}$.

Mathematics subject classification (2000): 47A63.

Keywords and phrases: Löwner-Heinz inequality, order preserving operator inequality.

\section{REFERENCES}

[1] T. ANDo AND F. HiaI, Log majorization and complementary Golden-Thompson type inequalities, Linear Alg. and Its Appl., 197, 198 (1994), 113-131.

[2] R. Bhatia, Positive Definite Matrices, Princeton Univ. Press, 2007.

[3] M. FuJII, Furuta's inequality and its mean theoretic approach, J. Operator Theory, 23 (1990), 67-72.

[4] M. FujII AND E. KAMEI, Mean theoretic approach to the grand Furuta inequality, Proc. Amer. Math. Soc., 124 (1996), 2751-2756. 
[5] M. Fuji, A. Matsumoto And R. NaKamoto, A short proof of the best possibility for the grand Furuta inequality, J. of Inequal. and Appl., 4 (1999), 339-344.

[6] T. FurutA, $A \geqslant B \geqslant 0$ assures $\left(B^{r} A^{p} B^{r}\right)^{1 / q} \geqslant B^{(p+2 r) / q}$ for $r \geqslant 0, p \geqslant 0, q \geqslant 1$ with $(1+2 r) q \geqslant$ $p+2 r$, Proc. Amer. Math. Soc., 101 (1987), 85-88.

[7] T. FURUTA, Elementary proof of an order preserving inequality, Proc. Japan Acad., 65 (1989), 126.

[8] T. FurutA, An extension of the Furuta inequality and Ando-Hiai log majorization, Linear Alg. and Its Appl., 219 (1995), 139-155.

[9] T. FURUTA, Simplified proof of an order preserving operator inequality, Proc, Japan Acad., 74 (1998), 114.

[10] T. FURUTA, Invitation to Linear Operators, Taylor \& and Francis, 2001, London.

[11] T. FURUTA, Further extension of an order preserving operator inequality, J. Math. Inequal., 2 (2008), 465-472

[12] T. Furuta, M. Hashimoto AND M. Ito, Equivalence relation between generalized Furuta inequality and related operator functions, Scientiae Mathematicae, 1(1998), 257-259.

[13] T. Furuta, M. YANAGIDA And T. YAMAZAKI, Operator functions implying Furuta inequality, Math. Inequal. Appl., 1 (1998), 123-130.

[14] E. HeInZ, Beiträge zur Störungsteorie der Spektralzerlegung, Math. Ann., 123 (1951), 415-438.

[15] E. KAMEI, A sattelite to Furuta's inequality, Math. Japon., 33 (1988), 883-886.

[16] E. KAMEI, Parametrized grand Furuta inequality, Math. Japon., 50 (1999), 79-83.

[17] K. LÖWNER, Über monotone MatrixFunktionen, Math. Z., 38 (1934), 177-216.

[18] G. K. Pedersen, Some operator monotone functions, Proc. Amer. Math. Soc., 36 (1972), 309-310.

[19] K. TAnahashi, Best possibility of the Furuta inequality, Proc. Amer. Math. Soc., 124 (1996), $141-$ 146.

[20] K. Tanahashi, The best possibility of the grand Furuta inequality, Proc. Amer. Math. Soc., 128 (2000), 511-519.

[21] T. YAmAZAKI, Simplified proof of Tanahashi's result on the best possibility of generalized Furuta inequality, Math. Inequal. Appl., 2 (1999), 473-477.

[22] J. Yuan And Z. GaO, Complete form of Furuta inequality, Proc. Amer. Math. Soc., 36 (2008), 2859-2867. 